\title{
GEO-HISTÓRIA DA BACIA DE CAMPOS, BRASIL: DO ALBIANO AO MAASTRICHTIANO
}

\author{
RICARDO LATGÉ MILWARD DE AZEVEDO*, JOSE GOMIDE* \\ e MARTA CLÁUDIA VIVIERS**
}

\begin{abstract}
The Cretaceous foraminifera fauna of nearly 50 wells drilled in the Campos Basin has been searched for paleoecological purposes. The paltogeographical development of the area has been reconstructed by means of maps concerning each of the stratigraphical intervals recognized. Marine sedimentation in the area began in the Early to Middle Albian with the deposition of carbonates in hypersaline, shallow nexitic environment. Later, during the Late Albian/Early Turonian, the regional bathymetric conditions became somewhat deeper (deep neritic/upper bathyal), thus allowing the system to attain normal salinity. During the same period the basin was submitted to an anoxic event of worldwide extent. In the Middle to Late Turonian, the ecological and geographical conditions were thoroughly modiffed by the settlement of bathyal environments over wide areas of the basin. Since then, during the whole Late Cretaceous, sediments were deposited under greater depths, though the water masses remained well oxygenated and allowed a textulariid benthic fauna thrive in the area.
\end{abstract}

INTRODUÇÃO Encontrados em quase todos os ambientes marinhos e estuarinos atuais, os foraminiferos bentônicos têm sido usados na reconstituição de ambientes antigos de sedimentação desde que Natland, na década de 30 , demonstrou a correspondência entre espécies vivas e formas neogênicas.

Este trabalho apresenta os resultados de estudo paleoecológico desenvolvido na seção marinha cretácea da Bacia de Campos, baseado no exame das associações de foraminíferos fósseis. Interpretações paleogeográficas são mostradas em forma de mapas, que ilustram a evolução da bacia do Albiano ao Maastrichtiano.

\section{LOCALIZAÇÃo E ESTRATIGRAFIA A área estu-} dada situa-se na parte oriental da Bacia de Campos, entre as coordenadas $40^{\circ}$ e $41^{\circ}$ de longitude oeste e $20^{\circ}$ e $21^{\circ}$ de latitude sul (Fig. 1).

0 arcabouço biocronoestratigráfico da seção baseia-se no zoneamento integrado de foraminíferos, nanofósseis e palinomorfos proposto por Azevedo et al. (1987). As designações litoestratigráficas referidas no texto, por sua vez, acompanham a nomenclatura formalizada por Schaller (1973). Foram analisadas somente a Formação Macaé e a parte cretácea da Formação Campos. O trabalho de Azevedo $e t$ al. (op. cit.) apresenta o quadro estratigráfico adotado neste estudo.

0 padrão estrutural e a distribuição dos reservatórios em ambas as formações foram controlados por processos de tectônica de sal, como demonstraram Figueiredo \& Mohriak (1984).

MÉTODOS Ao todo, 49 poços tiveram sua fauna de foraminíferos cretáceos identificada. Esses microorganismos foram recuperados de amostras de calha $\mathrm{e}$ de testemunhos, representativas, principalmente, de horizontes argilosos.

As interpretações paleoecológicas basearam-se na composição genérica dos foraminíferos bentônicos de cada amostra. Os foraminíferos planctônicos, metazoários e

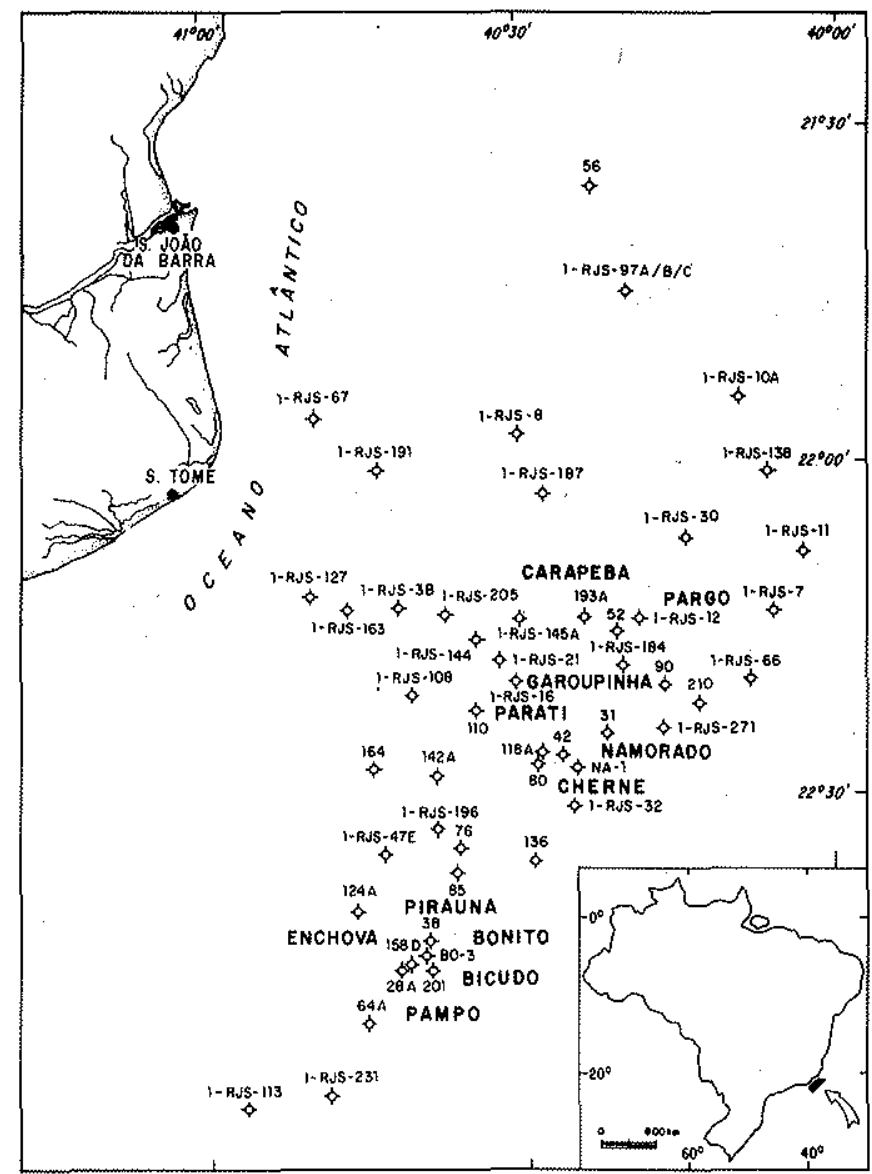

Figura 1-Mapa de localização

palinomorfos forneceram elementos secundários, porém úteis, para este tipo de análise. $O$ mesmo se pode dizer em relação às informaçōes de ordem quantitativa, física (preservação, coloração etc.) e litológica. 
Deduziu-se o paleoambiente de deposição a partir da comparação de cada associação faunística identificada com as descritas em Sliter \& Baker (1972), Scheibnerová (1981), Koutsoukos $(1984,1985)$ e artigos publicados em relatórios de progresso do Deep Sea Drilling Project (DSDP). Assim, foi possível posicionar as amostras nos diversos ambientes marinhos incluídos na classificação da Petrobrás.

O passo seguinte foi o mapeamento paleobatimétrico do topo das unidades biocronoestratigráficas mais uniformes na bacia. Para isto, obteve-se de cada poço o valor médio da amplitude batimétrica atribuída à amostra representativa do horizonte mapeado, para, então, traçar as curvas de isoprofundidade que limitam as principais feiçōes geomorfológicas de uma margem continental. E bom frisar que, devido à sistemática adotada em sua construção e ao grande número de amostras de calha utilizado, os mapas obtidos devem ser encarados como de tendência paleobatimétrica.

\section{CONSIDERACÓES PALEOAMBIENTAIS E GEOLOGI-}

CAS A seção analisada compreende os primeiros sedimentos matinhos não-evaporíticos depositados na Bacia de Campos. Formadas nas fases iniciais do processo de expansão do Oceano Attântico Sul, essas rochas exibem marcantes mudanças faunísticas que refletem as variações ecológicas de um ambiente instável. As interpretações paleogeográficas e paleoceanográficas alcançadas para o intervalo Albiano-Maastrichtiano são a seguir relatadas.

Albiano Inferior-Médio As primeiras associações fos* siliferas de origem marinha encontradas na bacia são atribuídas a essa idade e foram recolhidas dos carbonatos "pré-bota" ou Macaé Inferior (Falkeinhein 1981). Exibindo como principal característica um baixo índice de diversidade, essas associações são formadas, basicamente, por alguns gêneros de foraminíferos (Favusella, Lenticulina e outros nodosarídios, e Trocholina - este último mais comum na área norte) e raros metazoários, tais como equinóides, moluscos e ostracodes, destacando-se Conchoecia.

Dias-Brito (1982), analisando microbiofaciologicamente os calcilutitos do Macaé Inferior, então denominado unidade microbiofaciológica $\mathrm{I}$, demonstrou que sua deposiç̧ão ocorrera num ambiente marinho raso restrito, de águas quentes e oxigenadas, com fundos hipersalinos. Qualitativamente, a associação microfossilífera recuperada neste andar corresponde a essa interpretação. Além disso, constatou-se a presença de sais dessa idade no poço 1-RJS-3B, o que confirma a condição hipersalina das águas de fundo da bacia.

A figura 2 apresenta o mapa paleobatimétrico do topo do Albiano Inferior-Médio. Embora problemas de contaminação de amostra tenham dificultado a construção desta carta, reconheceram-se feiçőes geológicas significativas para o estudo evolutivo da bacia. Num exame preliminar do padrão de distribuição das curvas de isoprofundidade, constata-se a monotonia da plataforma carbonática albiana, que exibe um baixo gradiente com amplas áreas cobertas por lâminas đ'água não superiores a $30 \mathrm{~m}$. Próximo ao limite leste da área pesquisada, o declive do fundo era bem mais acentuado e definia faixas de ambiente nerítico médio e nerítico profundo.

Albiano Superior Este andar é representado nas porções central e leste da bacia por uma sequêencia de rochas

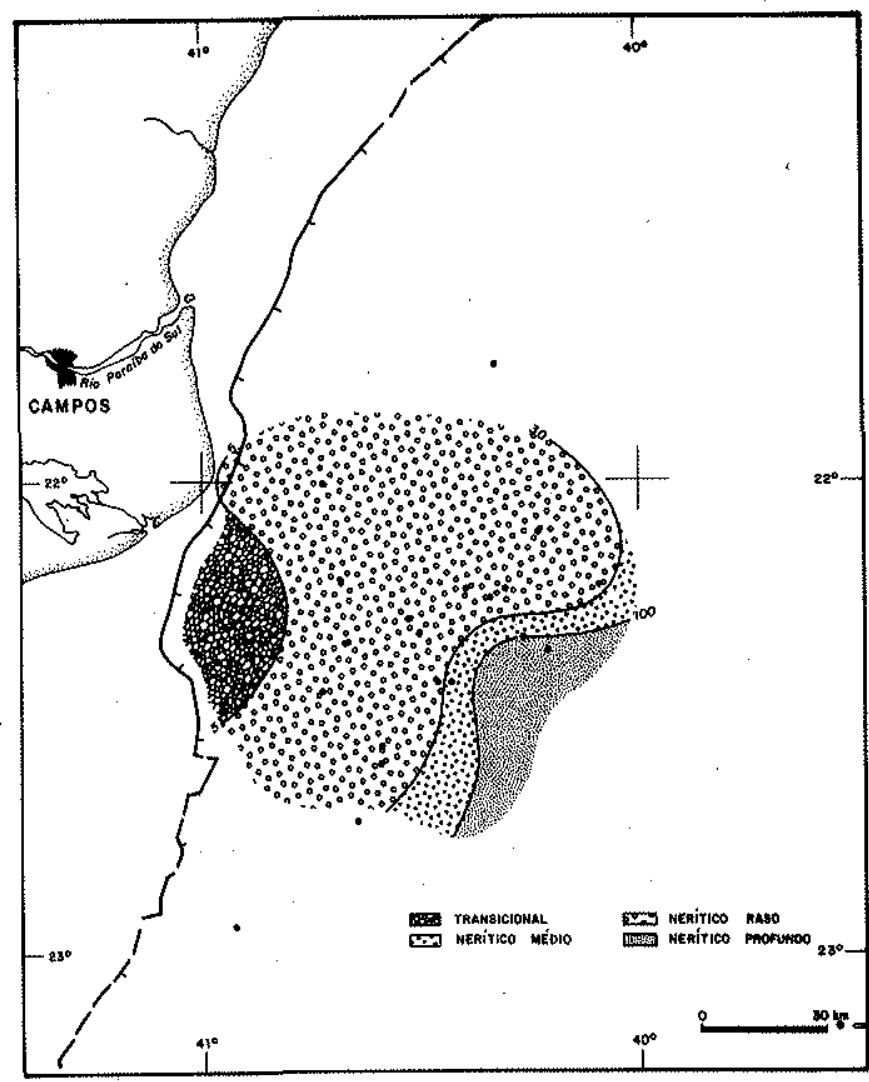

Figura 2 - Mapa paleobatimétrico do topo do Albiano Inferior-Médio

carbonáticas finas (calcilutitos e alguns níveis de marga) conhecida como "bota inferior" ou intervalo basal do Macaé Superior. Em seu interior, distinguem-se alguns horizontes estratigráficos, sendo o mais significativo o que limita os "intervalos maciço e Chalk" de Spadini (1982) e as unidades microbiofaciológicas II e III de Dias-Brito (1982). Faunisticamente, o Albiano Superior da Bacia de Campos é caracterizado pela abundância de planctônicos (foraminíferos, calcisferulídios e nanofósseis - os radiolários são bem menos freqüentes) e por uma razoável presença de foraminíferos bentônicos, notadamente os calcáriohialinos. Ao longo de toda a seção nota-se um progressivo aumento da diversidade e freqüência desses microfósseis, continuando tendência já registrada desde o final do Eo-Mesoalbiano.

Tal fato é atribuído ao inicio do processo de dessalinização das águas da bacia, em decorrência da umidificação progressiva do clima da área associada à expansão do Atlântico Sul (Dias-Brito 1982).

$\mathrm{O}$ conjunto de foraminiferos bentônicos encontrado nesse andar é formado pelos taxa Gyroidinoides aff. praestans, Osangularia utaturensis, Globorotalites michelinianus, Dorothia levis, D. oxycona, Lenticulina spp., $L$. gaultina, Lingulogavelinella frankei, Gavelinella spp., $G$. ex. gr. intermedia, Clavulina gabonica, Eponides? sp., Lagena apiculata, Cornoboides, Textularia, Pleurostomella, Saracenaria, Bolivina e Haplophragmoides. Embora nem sempre constituam uma única associação, essas formas distribuem-se por toda a área estudada e relacionam-se ao ambiente nerítico médio-profundo (de 30 a $200 \mathrm{~m}$ ). 
Fauna similar foi encontrada, também, em vários poços perfurados pelo DSDP (Scheibnerová 1981) e em diversos pontos na Europa e norte da África, anteriormente cobertos pelo Mar Tethys, comprovando assim seu caráter cosmopolita e a existência de comunicação entre o Atlântico Sul e o central no Neo-Albiano (Moullade \& Guerin 1982).

A presença de Favusella washitensis, Ticinella primula e Gavelinella ex. gr. intermedia reforça a interpretação de que águas quentes e rasas cobriam a Bacia de Campos durante este perfodo. $O$ conjunto de planctônicos observado é também ilustrativo de ambientes rasos já que raras são as formas quilhadas. A biota compõe-se, basicamente, de carapaças arredondadas e finas, similares às encontradas na porçẫo superior da coluna d'água dos mares atuais (Fig. 3). Situação um pouco diferente foi observada no poço 1-RJS-201, onde a presença de um bom número dos quilhados Rotalipora apenninica e Praeglobotruncana delrioensis indica uma sedimentação em ambientes mais profundos (batial superior?).

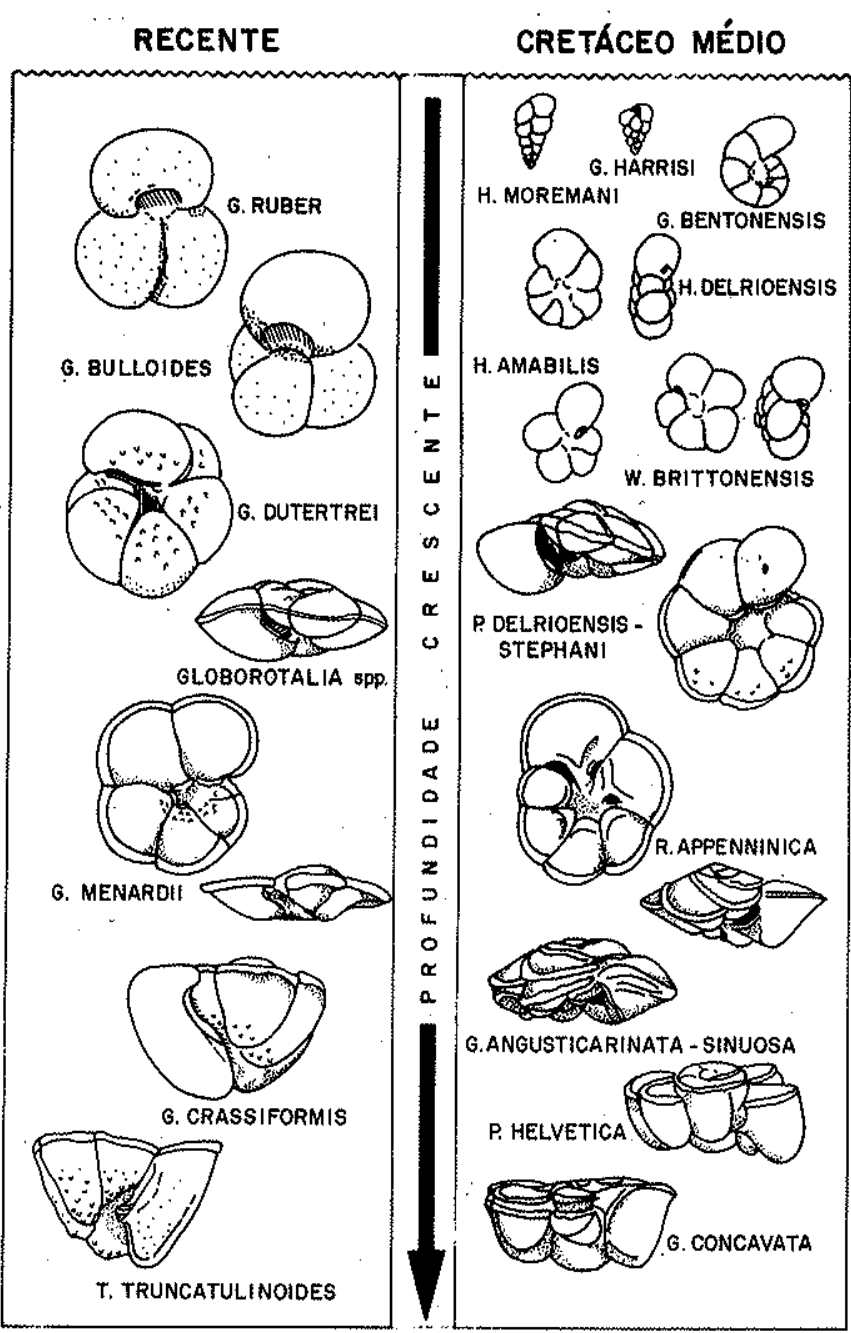

Figura 3 - Distribuição dos foraminiferos planctônicos na coluna d'água (modificado de Hart \& Bailey 1979)

Examinando o mapa paleobatimétrico obtido para o topo do Albiano Superior (Fig. 4), depreende-se que ocorreu, neste período, uma elevação relativa do nível do mar de pequena magnitude, porém suficiente para provocar o avanço em direção ao continente das curvas de isoprofundidades. Amplas áreas da bacia foram, então, submetidas à condição nerítico médio a profundo, reservando as paleobatimetrias maiores para a porção nordeste (de 200 a $300 \mathrm{~m}$ de batimetria), onde ocorria uma subsidência mais rápida.

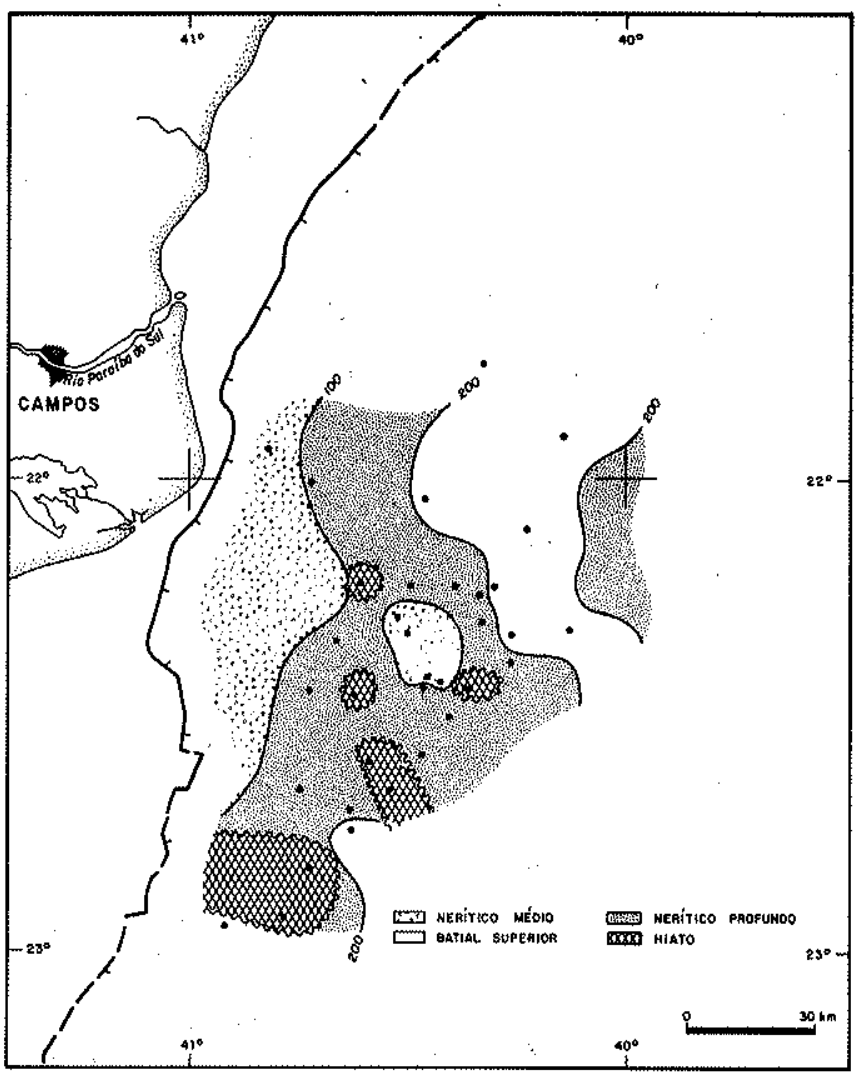

Figura 4 - Mapa paleobatimétrico do topo do Albiano Superior

Embora se considere que os sedimentos desse andar tenham coberto toda a Bacia de Campos, estes foram, total ou parcialmente, erodidos nos altos formados por falhamentos lístricos de grande rejeito com rotação associada (por exemplo, 1-RJS-205 e 1-RJS-196). Na área sul, a escavação de canyons durante o Neocretáceo e Terciário provocou, em alguns casos, o desaparecimento dos sedimentos do Albiano Superior.

Cenomaniano Inferior-Médio Adotou-se, aqui, a interpretação de Azevedo et al. (1987), que considera esta por* ção do Cenomaniano não ocorrer na bacia.

Cenomaniano Superior-Turoniano Inferior Estes andares são representados na Bacia de Campos por uma sucessão de margas, folhelhos e arenitos conhecida como "bota superior", intervalo argiloso (Spadini 1982) ou, ainda, unidade microbiofaciológica IV (Dias-Brito 1982). 
O conteúdo faunístico dessas rochas é totalmente diferente do reconhecido nos carbonatos albianos. Em seus estratos, os bentônicos são dominantes, destacando-se as textulariinas, normalmente amassadas e/ou com coloração clara. Os principais taxa reconhecidos foram o Haplophragmoides, Ammodiscus (pequenos), Trochammina, Glomospira (pequenas e delicadas), Ammobaculites, Clavulina gabonica e Dorothia oxycona. Entre os calcário-hialinos, foram encontrados com maior freqüência a Lenticulina, Gavelinella, Gyrodinoides aff. praestans, Lagena apiculata, Pleurostomella, Gyroidina, Globorotalites michelinianus, bolivinídios e nodosarídios.

0 paleozooplâncton é formado por foraminíferos $e$ radiolários. Entre os radiolários, as formas esféricas-lenticulares são amplamente dominantes. Os foraminiferos, por sua vez, pertencem aos gêneros Hedbergella, Heterohelix, Globigerinelloides e Whiteinella. Em algumas amostras, esses microfósseis ocorrem totalmente silicificados; é pro. vável que esta substituição tenha ocorrido durante o início da fase diagenética, com a sílica sendo liberada das carapaças opalinas dos radiolários.

De um modo geral, a distribuição dos foraminiferos ao longo da seção é bastante variada. Há níveis onde a diversidade genérica dos bentônicos é alta (25 gêneros em $120 \mathrm{~g}$ de sedimento), embora o mesmo nậo aconteça em. relação à frequêencia. Existem situações em que antbos os parâmetros apresentam baixos indices; isto é comum em amostras obtidas de depósitos turbidíticos ou de folhelhos formados em ambientes anaeróbicos. Esta condição anóxica pode ser identificada, também, em amostras microfossilíferas de testemunho, por uma monofauna de Neobulimina albertensis (?), taxon similar aos adaptados às bacias anóxicas atuais (Azevedo 1985). As figuras 5 e 6 ilustram graficamente a mudança faunistica ocorrida entre o Neo-Albiano e o Neocenomaniano-Eoturoniano, e os resultados geoquímicos (pirólise) observados nas margas e folhelhos do Macaé Superior. Os dados foram obtidos de um intervalo testemunhado continuamente pelo poço 1-CH-2-RJS.

Em termos paleoecológicos, interpreta-se que os últimos sedimentos da Formação Macaé se depositaram sob lâmina d'água de 100 a $300 \mathrm{~m}$, numa bacia relativamente pouco acidentada mas submetida a profundas variações hidroquímicảs. A inferência batimétrica é apoiada na associação bentônica e na ausência de planctônicos quilhados (Rotalipora e Praeglobotruncana). A topografia relativamente uniforme do fundo da bacia é demonstrada pela escassez de curvas de isoprofundidade no mapa paleobatimétrico (Fig. 7). As supostas variações nas condições hidroquímicas durante este período se baseiam na já referida mudança faunística, conseqüente ao processo de dessalinização e elevação relativa do nível do mar pós-albiana, e nos episódios turbidíticos e anóxicos reconhecidos na seção.

A porção superior da Formação Macaé não foi registrada na extremidade sudeste da área estudada e em janelas de origem erosiva dispersas pela bacia.

Turoniano Módio-Superior Raros são os registros deste andar na região de Campos. Nos poços onde foi encontrada a biozona diagnóstica (zona $D$. imbricata), a fauna bentônica associada é típica de ambiente batial e bastante similar à que será apresentada na próxima unidade cronoestratigrafica.

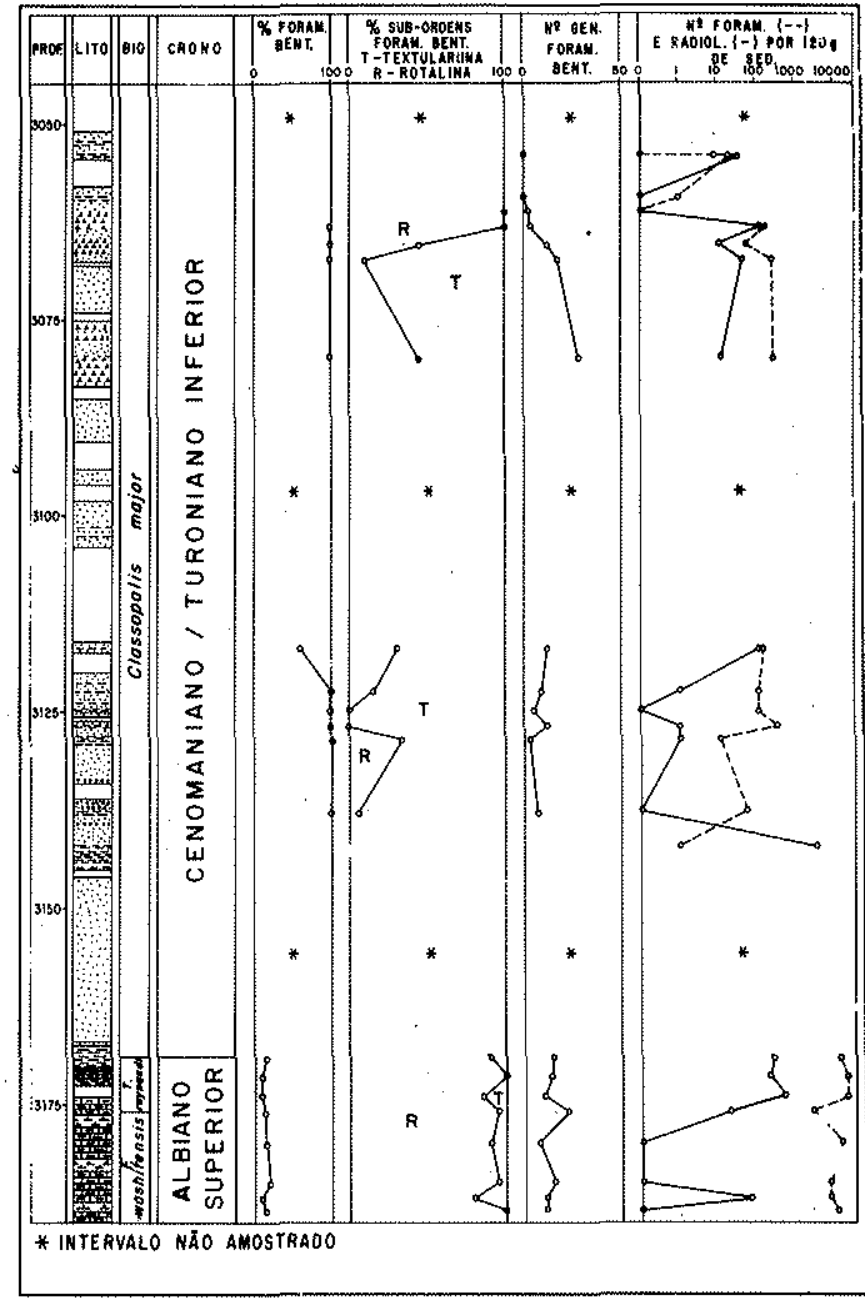

Figura 5 - Estudo quantitativo da fauna de foraminiferos $e$ radiolários de testemunhos do poco 7-CH-2-RJS (R. Rotaliina e T. Textularina)

Coniaciano-Santoniano Esta unidade é representada por folhelhos, margas e arenitos que constituem a porção inferior da Formação Campos.

A fauna observada nesses andares é bastante diversificada e de caráter oceânico. Nota-se o domínio das formas bentô. nicas, com destaque para Batkysiphon, Ammodiscus cretaceüs, Haplophragmoides, $H$. bulloides, Glomospira corona, G. charoides, Recurvoides, Trochammina, T. globigeriniformis, Textularia, Rzehakina, R. epigona, Gaudryna, G. pyramidata e Spiroplectammina, entre os aglutinantes, e Gavelinella, G. beccariformis, Lenticulina, Nodosaria, Osangularia, Lagena, L. apiculata, Gyroldinoides, Praebuli* mina, Pleurostomella e Valvulineria, entre os rotalídios.

$\mathrm{O}$ zooplâncton está representado nesta seção por radiolários e foraminiferos. Os primeiros concentram-se próximo ao topo da seção e exibem baixa diversidade, sendo freqüentes, apenas, os espécimes esféricos ou lenticulares. Já os foraminíferos distribuem-se de modo mais uniforme, embora sejam menos numerosos. Os principais taxa reconhecidos foram Marginotruncana sp., $M$. renzi, $M$. undulata, M. pseudolinneana, Globotruncana sp., G. fornicata, Dicarinella sp., $D$. algeriana, $D$. hagni, $D$. concavata, $D$. primitiva, Heterohelix sp. e raros hedbergelídeos.

Em qualquer análise preliminar da fauna dessa unidade é fácil diagnosticar o domínio do ambiente batial sobre a 


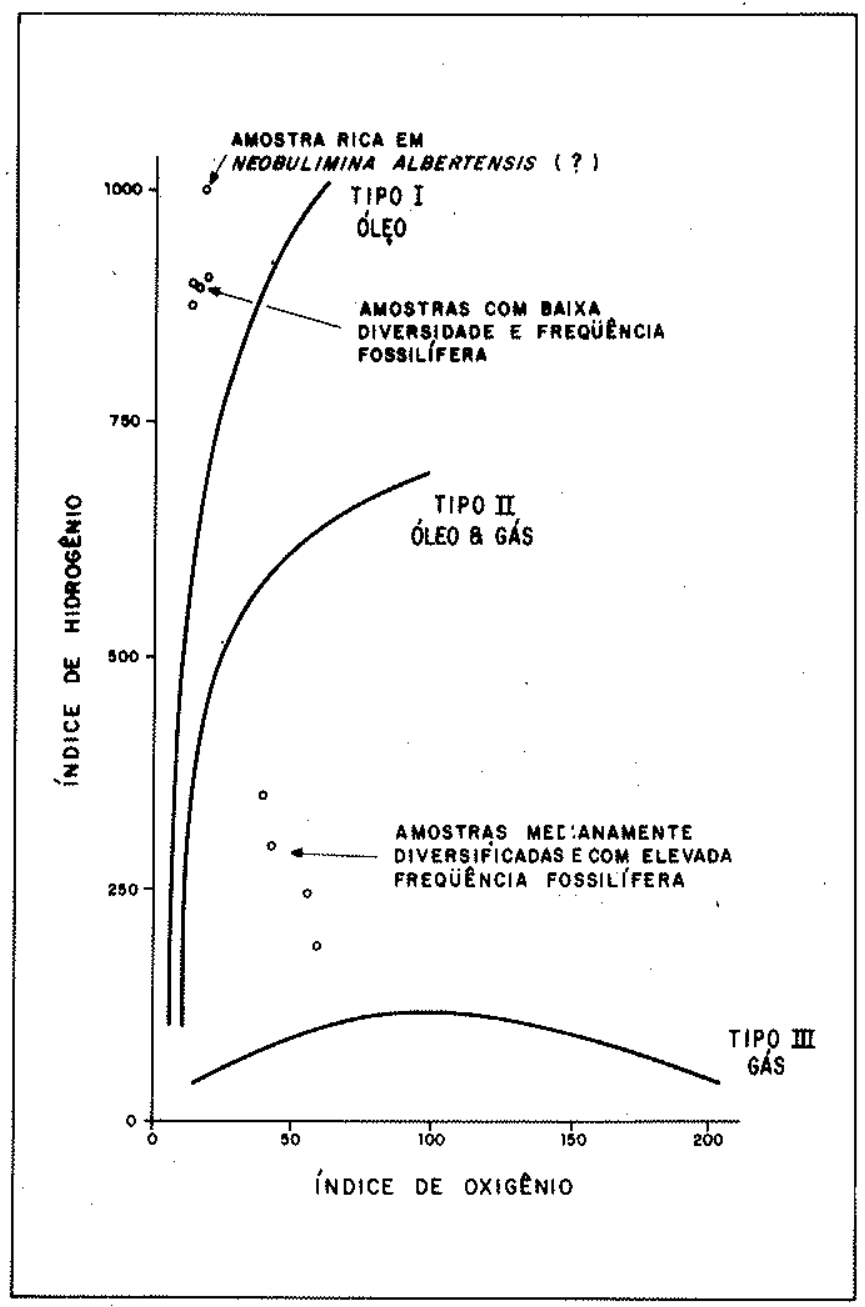

Figura 6 - Diagrama de Van Krevelen ilustrativo da condição anóxica de determinados horizontes do Cenomaniano - Superior-Turoniano Inferior

região. Estão presentes diversos bentônicos aglutinantes adaptados a águas profundas (batimetria superior a $500 \mathrm{~m}$ ) e um conjunto de planctônicos quilhados, pouco comuns em ambientes neríticos. Nos dois mapas paleobatimétricos obtidos, topo do Coniaciano, parte inferior (Fig. 8), e topo do Coniaciano, parte superior - Santoniano (Fig. 9), foram individualizados os três ambientes nos quais se subdivide o. meio batial. $O$ quadro 1 apresenta as associações fossilíferas que posṣibilitaram a construção desses mapas.

Num exame comparativo das curvas de isoprofundidades do topo dos andares Cenomaniano Superior-Turoniano Inferior e Coniaciano, parte inferior, constata-se uma nítida mudança ambiental, relacionada tentativamente ao episódio transgressivo eustático ocorrido no Coniaciano (Cooper 1977). A distribuição desigual desta unidade cronoestratigráfica na bacia, ocupando somente as partes central e leste, sugere feições de onlap compatíveis com um episódio de rápida elevação relativa do nível do mar, segundo os conceitos de Vail et al. (1977). A figura 10 apresenta uma seção dip, esquemática, exibindo as relações de onlap entre o Coniaciano, parte inferior e Coniaciano, parte superior do Santoniano e a Formação Macaé.

O mapa paleobatimétrico do Coniaciano, parte inferior, define, também, dois altos sindeposicionais na borda leste da bacia, relacionados a intrusão fgnea (?) (1-RJS-211) e
Quadro 1 - Associaçôes de microfósseis do Turoniano Superior-Santoniano representativas de ambientes paleobatimétricos

Nerítico profundo (100 a $200 \mathrm{~m})-$ Lenticulina, $G a$ velinella, Praebulimina, Osangularia, Gyroidinoides, Nodosaria, Lagena e Bathysiphon.

Nerítico profundo-batial superior $(100$ a $500 \mathrm{~m})$ Lenticulina, Gavelinella, Osangularia, nodosarídios, Bathysiphon, Praebulimina, Haplophragmoides, Lagena apiculata, Trochammina e Valvulineria.

Batial superior (200 a $500 \mathrm{~m}$ ) - Lenticulina, Bathy. siphon, Gyroidinoides, Haplophragmoides, nodosaridios, Praebulimina, Trochammina e Pleurostomella.

Batial superior-batial médio (200 a $1.000 \mathrm{~m})-B a$ thysiphon, Gaudryina, Haplophragmoides, Gavelinella beccariformis, Reussella, Glomospira corona, $G$. charoides, Rzeakina epigona, Trochammina, Lenticulina e Praebulimina.

Batial médio-batial inferior ( 500 a $2.000 \mathrm{~m})-$ Bathysiphon, Gavelinella beccariformis, Gyroidinoides, Ha* plophragmoides, Glomospira corona, G. charoides, Trochammina globigeriformis, Ammodiscus, Rzeakina epigona, Lenticulina, Gaudryina, Hormosina, Dorothia bulleta, Cyclammina cancellata, Spiroplectamina e Quinqueloculina lamarkina.

movimentação halocinética (em torno do 1-RJS-11).

Embora em termos faunísticos não se reconheçam diferenças significativas entre o Coniaciano, parte inferior e Coniaciano, parte superior-Santoniano, a história deposicional deste último intervalo foi algo diferente. Ilustrando a continuidade do processo de expansão da condição oceânica da bacia, as curvas de isoprofundidades para o topo desta última unidade posicionam-se ligeiramente deslocadas para oeste em relação às do mapa do topo do Coniaciano basal. A sedimentação estendeu-se à borda ocidental da bacia e as áreas de não-deposição ou erosão concentraram-se nas porçóes leste e sul, numa faixa de direção SW-NE, abrangendo os poços 1-RJS-3B, 1-RJS-187 e 1-RJS-97C. Ao longo do limite oriental, definiu-se uma feição positiva que servia de anteparo à progradação dos sedimentos para leste, concentrando-os na parte central da bacia.

Campaniano Poucos são os registros desta unidade cronoestratigráfica na bacia. As maiores concentrações estão localizadas em sua área central e em dois núcleos isolados na porção norte.

A associação faunística encontrada é indicativa de ambiente batial médio-inferior, ocorrendo um conjunto de bentônicos semelhante ao reconhecido em estratos do Coniaciano-Santoniano. Entre os plantônicos, destacam-se Globotruncana lapparenti, $G$. linneiana, $G$. fornicata, Heterohelix spp. e o nanofossil Eiffelithus eximius.

O hiato do Campaniano parece ser do tipo não-deposicional, desenvolvido numa bacia faminta. 


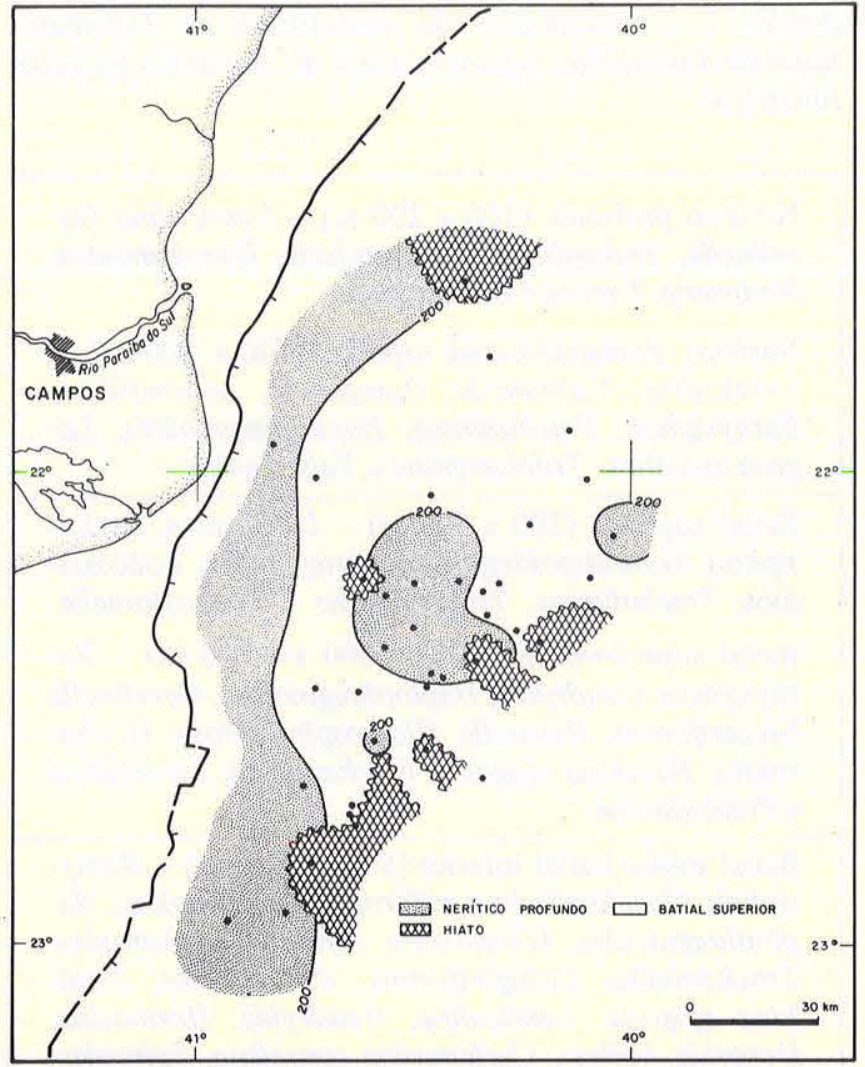

Figura 7-Mapa paleobatimétrico do topo do Cenomaniano Superior-Turoniano Inferior

Maastrichtiano Este andar é representado litologicamente por folhelhos e alguns arenitos turbidíticos que ocorrem com mais freqüência na região norte, onde a unidade atinge as maiores espessuras.

Constituído por uma associação fossilífera bastante diversificada, o Maastrichtiano exibe uma razão planctônico/ bentônico equilibrada, com maior número de aglutinantes entre os componentes bênticos, caracterizando o domínio batial em amplas áreas da bacia (Quadro 2).

Entre os planctônicos, os foraminíferos são bem mais numerosos, com os radiolários ocorrendo somente na área norte. Destacam-se os gêneros Globotruncana, Pseudotextularia, Pseudoguembelina e Heterohelix.

Examinando o mapa paleobatimétrico do topo deste andar (Fig. 11), nota-se, mais uma vez, o avanço das curvas de isoprofundidade para oeste. Distingue-se, também, um talude relativamente íngreme que acompanha o limite oeste da porção setentrional da área estudada, até as proximidades de Piraúna e Enchova, onde inflete para sudoeste e, em seguida, para sudoeste. Nas regióes central e leste, o declive do fundo era bem menor, com a paleobatimetria variando entre 1.000 e $1.500 \mathrm{~m}$.

$\mathrm{Na}$ área norte, essas duas feições geomorfológicas, talude e bacia, são separadas por uma calha de direção SW-NE. Sua inferência baseia-se na identificação, em cinco poços, de uma ecozona constituída exclusivamente de foraminíferos aglutinantes, bem desenvolvidos, típicos de águas profundas (Bathysiphon, Glomospira e Trochammina globigeriniformis, entre outros), sugerindo uma deposição abaixo do nível de dissolução de $\mathrm{CaCO}_{3}$. Em modelos recentes, esta condição é reconhecida em meio abissal ou em ambientes mais raros (batiais) submetidos a influxo elevado de terrígenos. Neste último caso, além da redução

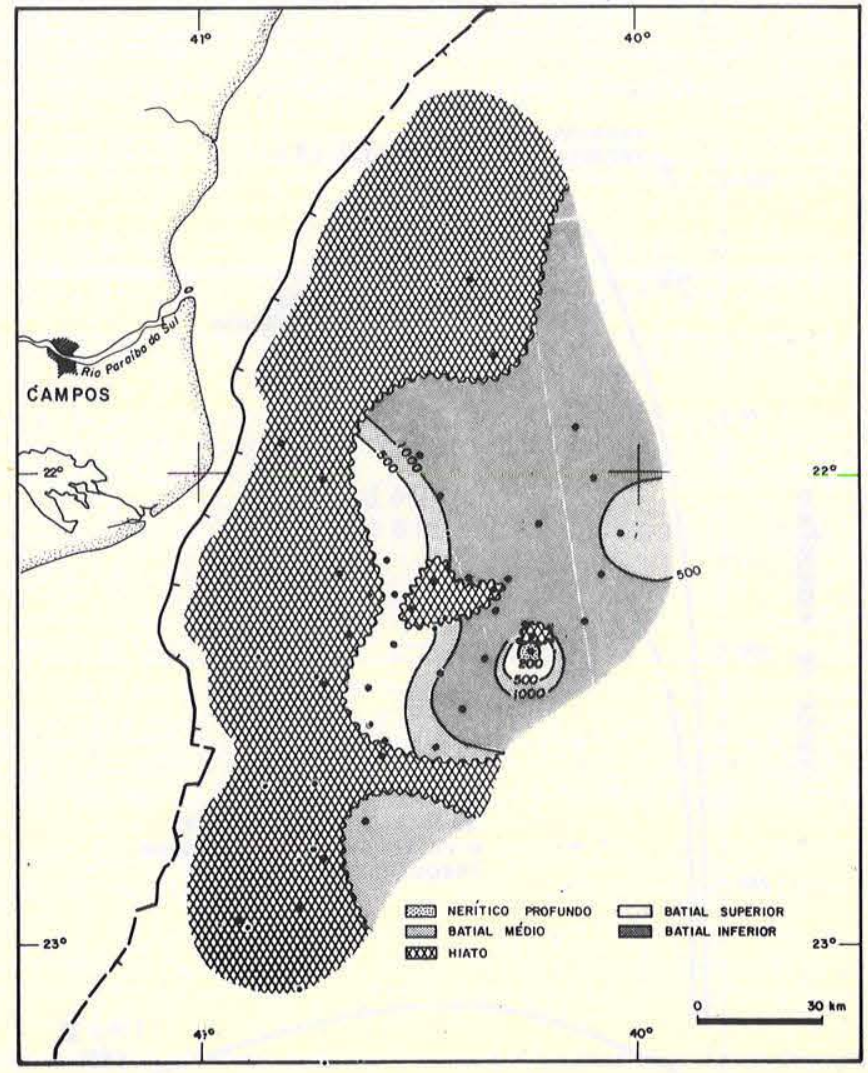

Figura 8 - Mapa paleobatimétrico do topo do Coniaciano parte injerior

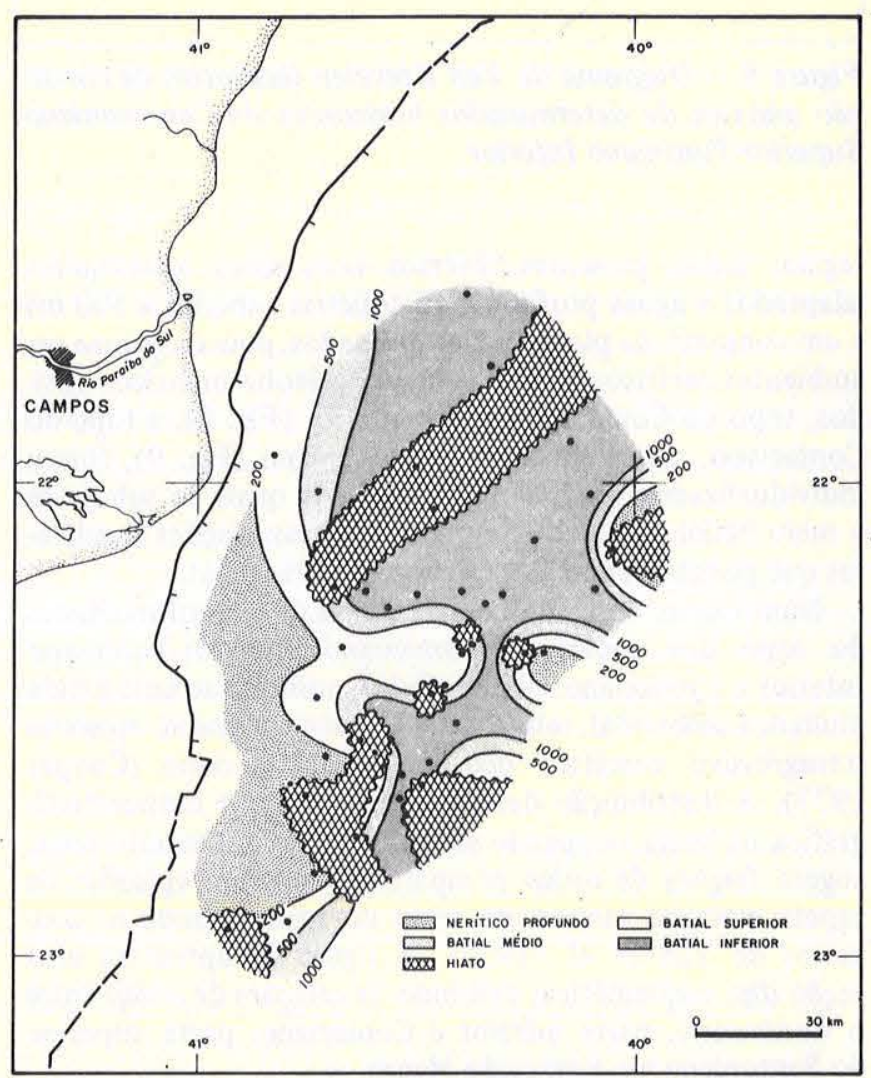

Figura 9 - Mapa paleobatimétrico do topo do Coniaciano parte superior-Santoniano 
dos teores de carbonato provocada pelo ingresso de água doce no sistema, ocorre o incremento do volume de matéria orgânica na bacia, causando intensa produção de $\mathrm{CO}_{2}$ e o correspondente decréscimo do $\mathrm{pH}$ (Hess \& Butt 1976). Embora não haja uma definição final sobre o significado desta anomalia faunística, considera-se razoável a hipótese de que ela representaria uma área receptora de grande aporte de terrígenos e, portanto, imprópria à preservação dos espécimes de parede carbonática; o reconhecimento de Azolla sp. reforça esta hipótese. Em termos paleobatimétricos, esta ecozona foi associada ao ambiente batial inferior com profundidades um pouco maiores que a média da região.

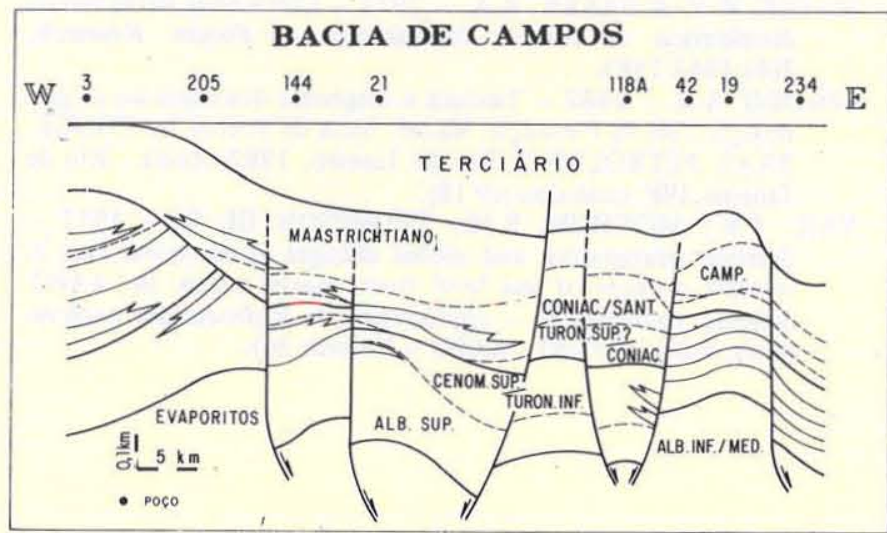

Figura 10 - Seção dip esquemática exibindo horizontes crono e sismoestratigráficos

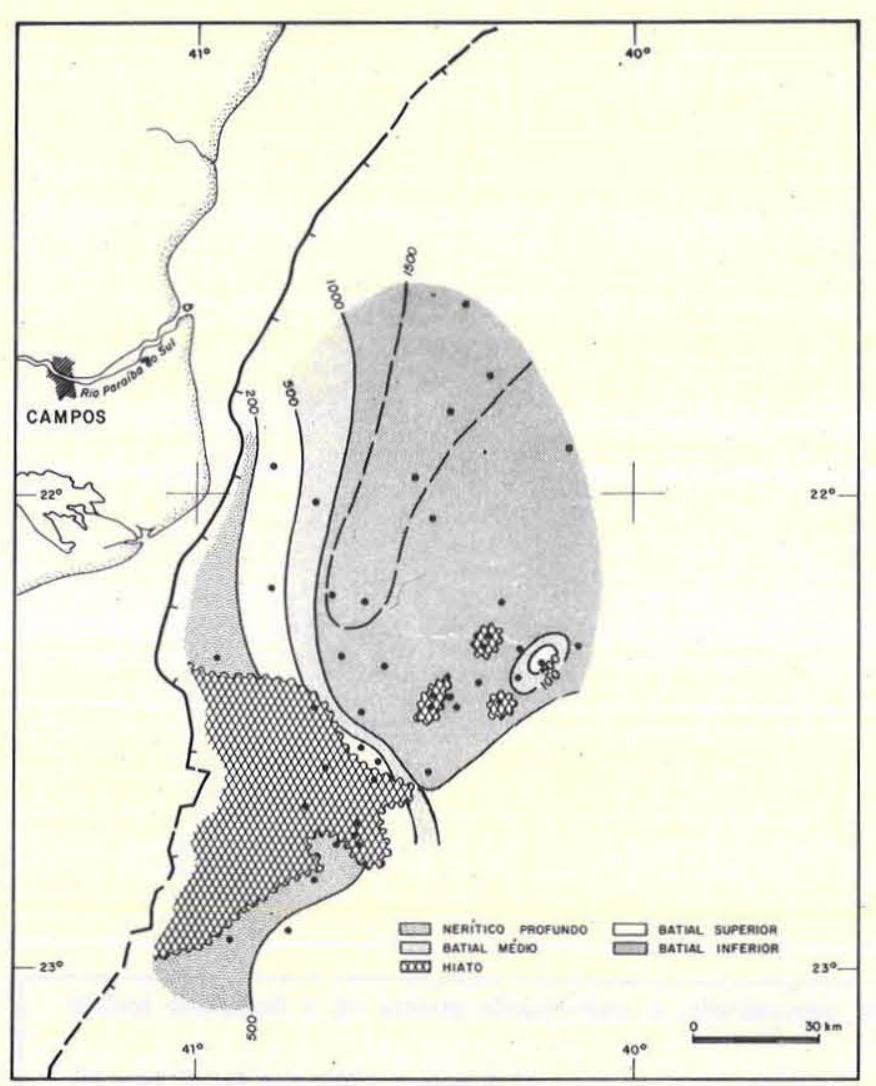

Figura 11 - Mapa paleobatimétrico do topo do Maastrichtiano Superior
Quadro 2 - Associações de microfósseis do Maastrichtiano representativas de ambientes paleobatimétricos

Nerítico profundo-batial superior (100 a $500 \mathrm{~m})-$ Lenticulina, Gavelinella, Osangularia, nodosarídios, Bathysiphon, Praebulimina, Haplophragmoides e Lagena apiculata.

Batial superior (200 a $500 \mathrm{~m})$ - Lenticulina, Bathysiphon, Gyroidinoides, Haplopragmoides, nodosarídios, Praebulimina, Trochammina e Pleurostomella.

Batial superior-batial médio (200 a $1.000 \mathrm{~m})-\mathrm{Ba}$ thysiphon, Gaudryna, Reussella szajnochae, Gavelinella, Glomospira corona, Haplophragmoides, Lenticulina, Textularia, Gaudryina, Dorothia, Praebulimina, Gyroidinoides e Bolivina incrassata.

Batial médio-batial inferior (500 a $2.000 \mathrm{~m})$ - Bathysiphon, Gavelinella beccariformis, Gyroidinoides, Haplophragmoides, Glomospira corona, G. charoides, Trochammina globigeriniformis, Bolivina incrassata, Ammodiscus, Rzehakina epigona, Recurvoides, Lenticulina, Gaudryina, Osangularia, Hormosina, Dorothia bulleta, Cyclammina cancellata, Spiroplectammina e Quinqueloculina.

Batial inferior (1.000 a $2.000 \mathrm{~m})$ - Bathysiphon, Haplophragmoides, Trochammina globigeriniformis, Spiroplectammina, Glomospira charoides, Cyclammina cancellata, Ammodiscus e pleurostonelídios.

Os sedimentos maastrichtianos estão ausentes na porção SW da bacia e em pequenos núcleos isolados de origem erosiva. Em torno dos poços 1-RJS-35 e 1-RJS-210, verificou-se um alto sindeposicional ativo desde o Coniaciano.

CONCLUSŐES A história da seção marinha cretácea pós-evaporítica iniciou-se no Eo-Meso-Albiano com a deposição de carbonatos em ambiente de águas rasas, quentes e hipersalinas.

Com a alteração climática e a elevação relativa do nível do mar ocorrida durante o Neo-Albiano, estabeleceu-se um processo de dessalinização das águas de fundo da bacia com a conseqüente diversificação da fauna bêntica neste substrato.

Sobre o Andar Albiano acumularam-se os sedimentos do Cenomaniano Superior-Turoniano Inferior sob condições paleobatimétricas mais profundas (média entre 200 a $300 \mathrm{~m}$ ). Evidências de episódios anóxicos e de correntes de turbidez foram reconhecidas neste intervalo.

Ao final do Mesocretáceo ocorreu uma interrupção na sedimentação na área estudada, possivelmente causada por uma elevação relativa do nível do mar de grande magnitude. No mesmo período, a bacia foi submetida a movimentações tectônicas que alteraram substancialmente seu perfil geomorfológico, com a delimitação de zonas de talude e bacinal.

A predominância das condições oceânicas sobre a região estendeu-se por todo o Neocretáceo. Durante este período, houve progressivo incremento paleobatimétrico, com a bacia atingindo, no final do Maastrichtiano, as condições paleoambientais mais profundas (em certos locais, superiores a $1.500 \mathrm{~m}$ ).

Agradecimentos Os autores expressam seus agradecimentos a todos os geólogos do Setor de Bioestratigrafia e Paleoecologia do Cenpes, que prestaram seu apoio a este trabalho; e à diretoria da Petrobrás, pela liberação do trabalho para publicação. 


\section{REFERÊNCIAS BIBLIOGRÁFICAS}

AZEVEDO, R.L.M. - 1985 - Estudo paleoecológico da Bacia do Espírito Santo, Brasil, com base em foraminíferos. In: Brasil-MME-DNPM, Col. Trab. Paleont., Brasília. Geologia 27: Paleontologia e Estratigrafia 2:261-171.

AZEVEDO, R.L.M.; GOMIDE, J.; VIVIERS, M.C.; HASHIMOTO, A.T. - 1987 - Bioestratigrafia do Cretáceo marinho da Bacia de Campos, Brasil. Rev. Bras. Geoc. 17(2): 147-153.

COOPER, M.R. - 1977 - Eustacy during the Cretaceous: its implications and importance. Paleogeogr., Paleoclimatol., Paleoecol., 22(1):1-60.

DIAS-BRITO, D. - 1982 - Evolução paleoecológica da Bacia de Campos durante a deposição dos calcilutitos, margas e folhethos da Formação Macaé (Albiano e Cenomaniano?). Bol. Téc. Petrobrás, 25(2):84-97.

FALKEINHEIN, F.U.H. - 1981 - Carbonate microfacies of the Macaé Formation, Campos Basin, offshore Brazil. Urbana, Univ. of Illinois. (Tese de Doutorado).

FIGUEIREDO, A.M.F. \& MOHRIAK, W.U. - 1984 - A tectônica' salífera e as acumulações de petróleo na Bacia de Campos. In: CONGR. BRAS. GEOL., 33, Rio de Janeiro, 1984. Anais... Rio de Janeiro, SBG. v. 3, p. 1380-1394.

HART, M.B. \& BAILEY, H.W. - 1979 - The distribution of planktonic foraminifera in the Middle Cretaceous of NW Europe. Aspekte der Kreide Europas. IUGS Series A, nọ 6, p. 527-542.

HESS, R. \& BUTT, A. - 1976 - Paleobathymetry of Cretaceous turbidite basins of the East Alps relative to the calcite compensations level. J. Geol., 84(2):505-533.

KOUTSOUKOS, E.A.M. - 1984 - Evolução paleoecológica do Albiano ao Maastrichtiano na área noroeste da Bacia de Campos, Brasil, com base em foraminíferos. In: CONGR. BRAS. GEOL., 33, Rio de Janeiro, 1984. Anais... Rio de Janeiro, SBG. v. 3, p. $685-698$.

KOUTSOUKOS, E.A.M. - 1985 - Distribuição paleobatimétrica de foraminíferos bentônicos do Cenozóico. Margem continental atlântica. In: Brasil MME-DNPM, Col. Trab. Paleont., Brasília. Geologia 27, Paleontologia e Estratigrafia 2:355-370.
MOULLADE, M. \& GUERIN, S. - 1982 - Le problème des relations de l'Atlantique Sul et de l'Atlantic Central au Crétacé moyen: nouvelles données microfauniques d'après le forage DSDP. Bull. Soc. Géol. France, 24(3):511-547.

NATLAND, M.L. - 1933 - The temperature and depth distribution of some recent and fossil foraminifera in the southern California region. Scripps Institute of Oceanography Technical Series. v. 3, p. 225-230.

SCHALLER, H. - 1973 - Estratigrafia da Bacia de Campos. In: CONGR. BRAS. GEOL., 27, Aracaju, 1973. Anais... Aracaju, SBG. v. 3, p. 247-258,

SCHEIBNEROVĀ, V. - 1981 - Paleogeographical implications of Cretaceous benthic foraminifera recovered by the Deep Sea Drilling in the Western South Atlantic Ocean. Cretaceous Research, 2:1-18.

SLITER, W.V. \& BAKER, R.A. - 1972 - Cretaceous bathymetric distribution of benthic foraminifers. J. Foram. Research, 2(4):1967-1983.

SPADINI, A.R. - 1982 - Textura e diagênese dos calcários de granulação fina da Formação Macaé, Bacia de Santos. In: CONGR. BRAS. PETROLEO 2, Rio de Janeiro, 1982. Anais... Rio de Janeiro, IBP. (trabalho n. ${ }^{\circ} 18$ ).

VAIL, P.R.; MITCHUM, R.M.; THOMPSON III, S. - 1977 Seismic stratigraphy and global changes of sea level. Part 3: relative changes of sea level from coastal onlap. In: AAPG. Seismic stratigraphic - applications to hydrocarbon explorations. Tulsa, p. 53-81. (AAPG - Memoir 26).

MANUSCRITO 399

Recebido em 30 de outubro de 1986 Revisão aceita em 30 de março de 1987

"Só com a mobilização criativa, propositiva, intelectual de sua comunidade, a universidade poderá vir a dedicar-se melhor ao seu papel de dinamizadora e revolucionadora das idéias". 